\title{
Avaliação da Iniciativa Selo UNICEF Município Aprovado - uma experiência participativa com utilização de métodos mistos
}

\section{Introdução}

Marcia Paterno Joppert Ana Cristina Matos ${ }^{2}$

Rogério Oliveira ${ }^{3}$ Clarice Knijnik ${ }^{4}$

Sueli de Lourdes Couto ${ }^{5}$ Marcia Facchina ${ }^{6}$ Lenira Machado ${ }^{7}$

Ada Maria Junqueira ${ }^{8}$

1 Consultora, membro do Comitê Gestor da Rede Brasileira de Monitoramento e Avaliação e diretora da Lazzooli Consultoria Ltda.

2 Coordenadora de Monitoramento e Avaliação do UNICEF Brasil.

3 Oficial de Monitoramento e Avaliação do UNICEF Brasil.

4 Especialista sênior em monitoramento e avaliação.

5 Consultora em monitoramento e avaliação.

6 consultora em gestão pública

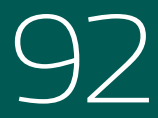

O modelo federativo brasileiro, introduzido pela Constituição de 1988, estabeleceu a autonomia nos entes subnacionais (estados e municípios) e as bases da descentralização das políticas públicas sociais. A autonomia concedida aos municípios abrange as áreas: política; normativa (para criar suas próprias leis tendo em vista aspectos locais); administrativa (para gerir sua administração e organizar serviços locais); e financeira (para estabelecer seus próprios impostos e investir sua receita própria). A descentralização das políticas públicas setoriais transferiu importantes responsabilidades aos municípios no sentido de assegurar e promover participação e controle social sobre as políticas públicas.
Essa autonomia e responsabilidades, no entanto, não foram acompanhadas da estrutura e recursos financeiros necessários aos novos desafios. Um dos principais problemas reside no fato de que um grande número de municípios ainda depende para sua sobrevivência, quase que exclusivamente, de transferências federais.

Nesse contexto, em relação às políticas de garantia dos direitos das crianças e adolescentes havia uma forte necessidade de apoiar as ações nos municípios que permitissem os rebatimentos dos avanços nas políticas e programas nacionais para o tema. As políticas nacionais voltadas para a garantia dos direitos das crianças e adolescentes têm um 
caráter transversal envolvendo diversos ministérios, as três instâncias administrativas e outros poderes, como legislativo e judiciário.

O Fundo das Nações Unidas para a Infância (UNICEF) tem como principal objetivo atuar no sentido de garantir os direitos das crianças e adolescentes em nível mundial, tal como previsto na Convenção sobre os Direitos da Criança, influenciando os tomadores de decisão e os diversos parceiros. Sua atuação abrange os direitos das crianças ao melhor começo de vida, pois o cuidado adequado nos primeiros anos constitui a base mais forte para 0 futuro de uma pessoa, o direito à educação, em especial das meninas; o direito à imunização contra doenças comuns da infância; e à boa nutrição, para prevenir que as crianças sofram ou morram de uma doença evitável.

Como parte do Programa de País, acordado a cada cinco anos com o Governo brasileiro em função das prioridades nacionais, - UNICEF realiza um trabalho de diálogo com as lideranças governamentais de nível federal e estadual e, sob a liderança das autoridades brasileiras, tem contribuído para a implantação do Pacto Um
Mundo Melhor para as Crianças e Adolescentes do Semiárido e a Agenda Criança Amazônia. No nível municipal, parte-se da premissa de que, além da disposição da prefeitura em aderir à iniciativa, os municípios implementam políticas e programas de nível federal, estadual e municipal. O município é o espaço privilegiado onde todas as políticas públicas acontecem e onde, portanto, os efeitos são gerados com a maior proximidade com o cidadão e, assim, com as crianças e adolescentes.

A partir da percepção do UNICEF sobre a importância de reforçar a gestão para resultados e a integração de políticas setoriais nos municípios para a ampliação dos impactos, foi criada, em trabalho conjunto com os Governos federal e do estado do Ceará, uma metodologia para a certificação de municípios que apresentassem avanço positivo em indicadores de gestão de políticas públicas, impacto social e participação social, num período de quatro anos, nas políticas setoriais com influência na garantia dos direitos das crianças e adolescentes. Esta certificação foi denominada Selo UNICEF Município Aprovado. A iniciativa teve sua primeira edição em 1999 no Ceará e foi sendo aprimorada ao longo das seis edições que a sucederam. 
A partir de 2005 foi ampliada a todos os onze estados do Semiárido brasileiro ${ }^{9}$ e, a partir de 2009 (última edição), aplicada aos nove estados da Amazônia Legal ${ }^{10}$.

O UNICEF Brasil tem avançado na direção de ampliar a iniciativa do Selo para novos municípios, e essa experiência tem sido vista por escritórios do Fundo de muitos países como boa prática de mobilização de um amplo espectro de atores para a garantia dos direitos das crianças e adolescentes em nível local, e de promoção de uma maior participação social nas políticas públicas com foco em equidade, imprimindo melhores capacidades de gestão para resultados. Pela intenção de aprimorar cada vez mais a iniciativa com base em lições aprendidas e pela possibilidade de replicá-la em outros países, o UNICEF, de acordo com sua política interna, decidiu promover um processo de avaliação independente. O objetivo é obter lições sobre o que está funcionando bem e identificar áreas onde é necessário trabalho complementar, de forma a continuar sua disseminação em novos municípios.

\section{DESCRIÇÃO DO}

OBJETO AVALIADO:

A INICIATIVA SELO UNICEF MUNICIIPIO APROVADO

\section{O OQUe É O SELO}

O Selo UNICEF Município Aprovado é uma metodologia que auxilia os municípios a mobilizar atores, capacitar técnicos, planejar ações voltadas à garantia dos direitos das crianças e adolescentes, acompanhar e avaliar seus resultados, permitindo ao UNICEF conferir um reconhecimento internacional àqueles que mais conseguem avançar, em um ciclo de quatro anos. A metodologia define o processo e os instrumentos de trabalho e atua basicamente em três eixos: gestão de políticas públicas, participação social e impacto social. Dentre os principais instrumentos metodológicos estão indicadores de gestão de políticas públicas e de impacto social, os quais são definidos, em cada edição, em conjunto com as áreas nacionais de governo responsáveis pelas políticas voltadas à infância e adolescência. Outro instrumento importante da metodologia é a participação social, que atua no sentido de mobilizar gestores e comunidade, especialmente jovens, convidando-os a observar, acompanhar e transformar a realidade em que vivem meninas e meninos.

O Selo é também uma das estratégias utilizadas pelo UNICEF para implantar o Programa de País acordado com o governo brasileiro e, portanto, um apoio para alcançar os objetivos e as metas com que o Governo Federal e os governadores dos nove Estados do Nordeste, de Minas Gerais e do Espírito Santo se comprometeram, em junho de 2004, no Pacto Nacional Um Mundo Melhor para a Criança e o Adolescente do Semiárido (Pacto) ${ }^{11}$ e que sete governadores da Amazônia Legal assumiram, em junho de 2008, na Agenda Criança Amazônia (ACA). ${ }^{12}$ 
É importante mencionar que os objetivos do Selo estão em consonância com a Declaração do Milênio, assinada pelo Brasil e por outros 189 países em setembro de 2000, durante a Cúpula do Milênio. Nela, os países se comprometeram a alcançar os oito Objetivos de Desenvolvimento do Milênio ${ }^{13}$ (ODM) até 2015.

\section{OBJETIVOS GERAL E ESPECÍFICOS}

Segundo o UNICEF, ${ }^{14}$ o Selo tem como objetivo geral fortalecer as políticas públicas de promoção de direitos das crianças e adolescentes nos municípios participantes e como objetivos específicos a utilização da metodologia para contribuir de modo sinérgico com outras iniciativas para:

\section{- Mobilizar Governos e sociedade civil} em torno do tema, como condição para a conscientização da sociedade sobre a importância do Estatuto da Criança e do Adolescente (ECA) e, por consequência, da priorização da agenda dos direitos da infância e adolescentes nas políticas públicas de todos os níveis;

- Desenvolver capacidades dos municípios para: planejar, implementar, monitorar e avaliar suas políticas de forma participativa, estimulando uma cultura de gestão para resultados na gestão municipal;

- Promover articulação entre os diversos parceiros visando à potencialização dos impactos; e

- Comunicar-se com os diversos segmentos sociais sobre a importância da agenda da infância e adolescência.

\section{ABRANGÊNCIA}

Dos 5.565 municípios existentes em 2012 no Brasil, 2.327 (41,8\%) pertencem às regiões do Semiárido e da Amazônia Le-

$9 \mathrm{AL}, \mathrm{BA}, \mathrm{CE}, \mathrm{ES}, \mathrm{MA}$ (parte), MG, PB, PE, PI, RN e SE.

10 AC, AM, AP, PA, RO, RR, MT, MA (parte) e TO.

11 Consultar: http://www.unicef.org/brazil/pt/where_9762.htm

12 Consultar: http://www.unicef.org/brazil/pt/where_12407.htm

13 Consultar: http://www.objetivosdomilenio.org.br

14 UNICEF. Termos de referência dos trabalhos de avaliação contratados pelo UNICEF. 
gal, onde viviam, em 2009, 22 milhões de crianças e adolescentes $(36,7 \%$ do total de crianças e adolescentes do Brasil). Destes, 2.003 (87\%) inscreveram-se na última edição do Selo (2009-2012) e foram ganhadores 425 (21\% dos inscritos).

\section{PROCESSO DE IMPLEMENTAÇÃO NOS MUNICÍPIOS}

\section{A cada edição do Selo, o UNICEF publica} um Guia Metodológico contemplando as orientações específicas aos municípios do Semiárido e para a Amazônia Legal. Esta publicação tem servido como referência para orientar as autoridades, gestores públicos, lideranças comunitárias, organizações não governamentais, associações locais e demais cidadãos no município que se interessem em participar e acompanhar a implantação do processo Selo UNICEF, com especial ênfase na participação de crianças e adolescentes. Na Figura 1, a seguir, apresentam-se as etapas de implantação da Iniciativa no período 2009-2012.

FIGURA 1: PROCESSO DE IMPLEMENTAÇÃO DA INICIATIVA SELO UNICEF NO PERÍODO 2009-2012.

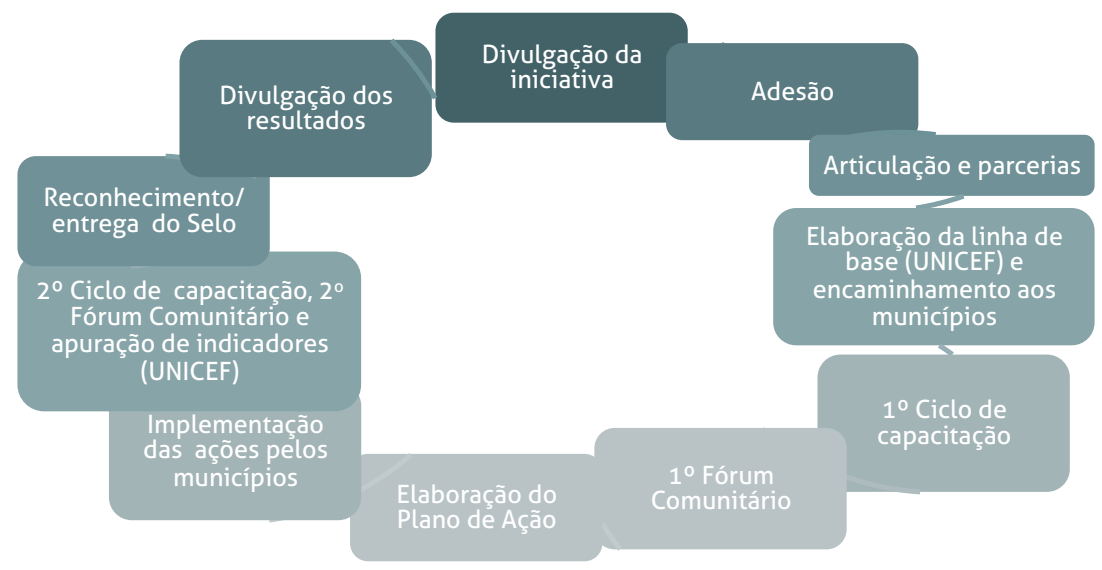

Fonte: IBGE, Censo Demográfico 2000/2010. 
Todo esse processo (com exceção da divulgação dos resultados) acontece em quatro anos, coincidindo com o período de gestão dos governos municipais, mas não de forma concomitante, porém, com os períodos de gestão estaduais e federal.

\section{ARRANJO INSTITUCIONAL DO SELO}

O arranjo institucional estabelecido para o Selo permite envolver territorialmente o conjunto de atores que podem contribuir para o alcance de seus objetivos nas duas regiões selecionadas para a intervenção.

Por parte do UNICEF, é utilizada sua própria estrutura, que contempla um escritório nacional em Brasília e oito escritórios zonais sediados em Belém, Fortaleza, Manaus, Recife, Rio de Janeiro, Salvador, São Luís e São Paulo. Esta estrutura guarda certa correspondência com os demais grupos de stakeholders. No nível federal, o escritório sede do UNICEF realiza a articulação com os ministérios, responsáveis pela formulação das políticas voltadas para a infância e adolescência. Juntos, UNICEF e Governo definem quais indicadores serão utilizados em cada edição. No nível estadual, os chefes de escritório articulam-se com os governos estaduais solicitando seu apoio de diversas formas no processo do Selo. Em geral, existe um ponto focal para o Selo no
Estado, que, na maioria dos casos, coincide com o ponto focal do Pacto ou da ACA. É no nível municipal que ocorre a principal interação com o UNICEF, realizada pelas equipes dos escritórios zonais e equipes de profissionais de apoio para capacitações, organização de oficinas e fóruns e avaliação local.

O modelo de governança nos municípios é estruturado de acordo com as recomendações do Guia Metodológico, do qual fazem parte o Conselho Municipal dos Direitos da Criança e do Adolescente (CMDCA), como protagonista, o articulador local, o prefeito, as Secretarias Municipais, a Comissão Pró-Selo e o Conselho Tutelar, definindo o papel de cada um.

\section{TEORIA DE MUDANÇA}

Ainda que o Selo seja considerado e definido como uma metodologia, a necessidade de avaliá-lo tornou fundamental a compreensão de sua Teoria de Mudança, encadeando insumos, atividades, outputs, outcomes e impactos. Esta elaboração foi resultado de um consenso entre a equipe de avaliação e o Comitê de Avaliação (ESC) e visou firmar a base do processo de avaliação, com vistas a aplicar os critérios demandados pelo UNICEF. O quadro a seguir apresenta o resultado. 


\section{- OUADRO 1: TEORIA DE MUDANÇA DO SELO UNICEF NOS MUNICÍPIOS}

\begin{tabular}{|c|c|c|c|c|}
\hline INSUMOS & ATIVIDADES & $\begin{array}{l}\text { PRODUTOS } \\
\text { (OUTPUTS) }\end{array}$ & $\begin{array}{l}\text { PRODUTOS } \\
\text { (OUTCOMES) } \\
\text { FINALIDADE E } \\
\text { PROPÓSITO }\end{array}$ & IMPACTOS \\
\hline $\begin{array}{l}\text { Estrutura UNICEF } \\
\text { com capacidade de } \\
\text { inserção no municí- } \\
\text { pio e neutralidade } \\
\text { política } \\
\text { Recursos Financei- } \\
\text { ros, humanos e tec- } \\
\text { nológicos (UNICEF e } \\
\text { parceiros) } \\
\text { Políticas Públicas } \\
\text { Federais/Marco } \\
\text { Legal/ ECA/ Conven- } \\
\text { ções Internacionais } \\
\text { - Programa de Pais } \\
\text { UNICEF } \\
\text { Dados, informações } \\
\rightarrow \text { indicadores } \\
\text { Metodologia } \\
\text { simples associada a } \\
\text { objetivos e metas/ } \\
\text { regras claras } \\
\text { Estrutura e } \\
\text { governança local } \\
\text { (Unidade Adminis- } \\
\text { trativa Local)/outros } \\
\text { recursos e política } \\
\text { local } \\
\text { Sistema de Comuni- } \\
\text { cação e informação } \\
\text { entre UNICEF e } \\
\text { municípios } \\
\text { Comunicação entre } \\
\text { gestores do Selo e } \\
\text { sociedade civil local }\end{array}$ & $\begin{array}{l}\text { Processo de Adesão } \\
\text { com critérios claros } \\
\text { Mobilização nos mu- } \\
\text { nicípios candidatos } \\
1^{0} \text { Fórum Comuni- } \\
\text { tário nos municípios } \\
\text { candidatos/ diagnós- } \\
\text { tico participativo } \\
\text { Treinamento de } \\
\text { participantes } \\
\text { Elaboração do Plano } \\
\text { de Ação }{ }^{15} \\
\text { Implementação do } \\
\text { Plano de Ação } \\
\text { Implementação de } \\
\text { outras políticas, } \\
\text { ações, parcerias } \\
\text { Monitoramento } \\
\text { Apuração dos } \\
\text { resultados: UNICEF + } \\
\text { parceiros } \\
2^{\circ} \text { Fórum Comuni- } \\
\text { tário } \\
\text { Emissão do Selo }\end{array}$ & $\begin{array}{l}\text { Mobilização de } \\
\text { cidadãos, governo e } \\
\text { sociedade para conso- } \\
\text { lidar e integrar políticas } \\
\text { locais que objetivem } \\
\text { melhorar os padrões de } \\
\text { vida das C\&A } \\
\text { Troca de experiên- } \\
\text { cias/ promoção de } \\
\text { networking entre vários } \\
\text { setores de governo } \\
\text { Reconhecimento do } \\
\text { município } \\
\text { Maior conscientização } \\
\text { local sobre as políticas } \\
\text { de infância e adoles- } \\
\text { cência/ECA } \\
\text { Maior capacidade local } \\
\text { para formular, planejar, } \\
\text { implementar, monitorar } \\
\text { e avaliar políticas de } \\
\text { infância e adolescência } \\
\text { Maior articulação entre } \\
\text { políticas públicas em } \\
\text { nível local } \\
\text { Maior capacidade de } \\
\text { parcerias para aprimo- } \\
\text { rar políticas públicas } \\
\text { de C\&A } \\
\text { Maior participação da } \\
\text { sociedade civil, em } \\
\text { especial dos jovens, na } \\
\text { formulação e acompa- } \\
\text { nhamento das políticas } \\
\text { públicas }\end{array}$ & $\begin{array}{l}\text { Conscientização das } \\
\text { sociedades locais } \\
\text { sobre o Estatuto da } \\
\text { Criança e do Adoles- } \\
\text { cente } \\
\text { Melhores políticas e } \\
\text { ações sociais para a } \\
\text { causa das crianças } \\
\text { e adolescentes nos } \\
\text { municípios }\end{array}$ & $\begin{array}{l}\text { Melhor quali- } \\
\text { dade de vida } \\
\text { para crianças e } \\
\text { adolescentes, afe- } \\
\text { rida por meio de } \\
\text { indicadores de: } \\
\text { - Impacto social } \\
\text { - Melhor gestão de } \\
\text { políticas públicas } \\
\text { - Participação } \\
\text { Social } \\
\text { Contribuição para } \\
\text { outros países em } \\
\text { desenvolvimento } \\
\text { (sul-sul) }\end{array}$ \\
\hline
\end{tabular}


A reconstrução da Teoria de Mudança permitiu revisitar o conjunto das questões formuladas, orientadoras da avaliação e concentradas em obter evidências sobre os resultados e efeitos imediatos do Selo UNICEF e sua efetividade nos municípios, aferidos por meio dos indicadores definidos. A premissa é que a mudança de cenário ocorre a partir do grau de envolvimento do município na metodologia utilizada pelo Selo e na mobilização de cidadãos, governo e sociedade para consolidar e integrar políticas locais capazes de melhorar os padrões de vida das crianças e adolescentes em cada município aprovado. Uma análise dos insumos listados na matriz mostra o grau de complexidade do ambiente de implementação do Selo. Trata-se de um país federativo, de acordo com a Constituição Federal, onde as 3 instâncias têm autonomia, responsabilidades e papéis nas políticas públicas voltadas para a criança e o adolescente. Outras iniciativas de nível local são implementadas, complementando as demais. Há também uma estrutura institucional no município e um modelo de governança. Ou seja, o Selo parte da premissa de que existem recursos que poderão ser potencializados por uma estratégia que imprima maior sinergia e articulação entre as diferentes iniciativas que estão acontecendo naquele espaço. 0 Selo atua, portanto, como um catalisador, no espaço social, cultural, político e econômico dos municípios.
Os resultados (outputs e outcomes) do Selo dependem de como se combinam os fatores existentes, descritos acima, e o fator exógeno trazido pelo UNICEF, que pretende favorecer a obtenção dos resultados. Ou seja, o Selo não constitui uma iniciativa isolada que possa gerar impactos em si.

\section{O CONTEXTO}

De acordo com dados estatísticos de 2009, o Brasil era o quinto maior país do mundo em termos de população e área geográfica, sendo a oitava economia mais rica. Os 190 milhões de habitantes dos 5.565 municípios do País incluíam 60 milhões de crianças e adolescentes, dos quais $51 \%$ eram meninos e $49 \%$ meninas. Do total, 30\% (57 milhões) viviam em nove áreas metropolitanas. Parte dessa população enfrenta a exclusão, principalmente aqueles que vivem em bairros menos favorecidos.

Cerca de 35 milhões de pessoas - 13 milhões de crianças e adolescentes - vivem no Semiárido e 24 milhões - 9 milhões de crianças e adolescentes - vivem na Amazônia Legal, com os menores índices de desenvolvimento humano. Crianças, adolescentes, indígenas e afro-brasileiros de todas as idades constituem grupos atingidos pela pobreza. A erradicação da pobreza extrema (ODM 1) continua constituindo

15 BRASIL. Ministério da Saúde. Boletim Epidemiológico do Ministério da Saúde de 2010. 
o principal objetivo social do atual governo do Brasil. Em 2010, embora 97\% das crianças e dos adolescentes entre 07 e 14 anos de idade frequentassem a escola no Brasil, 821 mil estavam fora do sistema educacional. Entre adolescentes de 15 a 17 anos, chega a 1,7 milhão o número dos que não estão matriculados na escola e, a cada ano, 400 mil estudantes do Ensino Médio abandonam os estudos antes do final do curso. Crianças e adolescentes com deficiência são especialmente excluídos do sistema.

Com relação à mortalidade infantil (ODM 4), entre 1990 e 2008, a taxa de mortalidade de menores de 5 anos caiu 57,5\% e a taxa de mortalidade de menores de 1 ano de idade caiu 59,7\%. No entanto, enquanto as regiões Sudeste e Sul alcançaram a meta do ODM 4 em 2008, isso ainda não ocorreu nas regiões Norte e Nordeste. A taxa de mortalidade de menores de 1 ano nas populações indígenas - 41,9 por mil nascidos vivos - fica mais de duas vezes acima da taxa nacional oficial mais recente. Apesar dos progressos em relação à saúde materna (ODM 5), cuja meta é a redução em três quartos da mortalidade materna, progressos foram alcançados a partir de muitos programas federais, melhorando a taxa de mortes por cem mil partos de bebês nascidos vivos. Embora as taxas de fertilidade tenham diminuído com regularidade para todos os grupos etários, o número de gestações em meio a meninas entre 10 e 14 anos de idade vem aumentando ligeiramente nos últimos anos.
Em 2010, aproximadamente 630 mil brasileiros viviam com o Vírus da Imunodeficiência Humana (HIV). ${ }^{16}$ Dos 593 mil casos de Síndrome de Imunodeficiência Adquirida (AIDS) relatados de 1980 até 2010, 32 mil eram de crianças e adolescentes menores de 19 anos de idade. Em meio a adolescentes de 13 a 19 anos de idade, há dez casos entre meninas para cada oito entre meninos. De acordo com o Mapa da Violência de 2004, os homicídios entre jovens vitimam fundamentalmente a população de sexo masculino (cerca de $93 \%$ das vítimas são homens) e de raça negra, que têm vitimização 65\% maior em relação à população total e $74 \%$ superior entre jovens.

O Selo foi proposto considerando o contexto da descentralização de políticas públicas, definido a partir da Constituição de 1988, que estabeleceu autonomia entre os entes federativos e o compartilhamento da gestão das políticas sociais. O marco legal definido pelo Estatuto da Criança e do Adolescente ${ }^{17}$ deu origem a uma série de políticas públicas voltadas à garantia dos direitos de C\&A. A partir de então, foram progressivamente sendo construídas e aprimoradas bases de dados dos setores saúde e educação com informações alimentadas pelos próprios municípios.

O Selo surge da constatação das dificuldades enfrentadas por grande parte dos municípios em implementar políticas públicas de garantia dos direitos das crianças e adolescentes, de modo transversal e intersetorial, e de suas fragilidades em termos de capa- 
cidades institucionais para arcar com todas as responsabilidades relativas à implementação das políticas sociais e de uma percepção de que uma estratégia como a do Selo poderia ajudar o nível federal a alcançar e mobilizar os municípios em torno das metas nacionais. Foi lançado em 1999 no Ceará, a partir de uma parceria entre o Governo do Estado e do UNICEF/CE, o qual tinha um desejo e via a necessidade de fazer a sociedade conscientizar-se sobre o ECA.

A ideia do Selo UNICEF foi evoluindo ao longo de sua história, culminando em uma ferramenta de mobilização da sociedade em torno dos ODM na esfera municipal. No Brasil, dadas as suas especificidades de gestão de políticas públicas e os avanços do marco regulatório das políticas sociais, os municípios têm assumido papel fundamental em relação às políticas de garantia dos direitos das crianças e adolescentes.

O Selo teve diversas edições, conforme mostra a Figura 2, que também aponta sua abrangência. Os resultados alcançados e a vontade política de diferentes atores tornaram possível a expansão da estratégia em 2005 para os 11 estados do Semiárido como uma contribuição do UNICEF para o Pacto Um Mundo Melhor para Crianças e Adolescentes do Semiárido Brasileiro. Em 2009 o Selo foi estendido para municípios da Amazônia Legal como uma contribuição do UNICEF para o cumprimento da Agenda Criança Amazônia, lançada em 2008. Nesta edição também ocorre uma grande mudança: o período de implementação do Selo passa a ser de 4 anos.

\section{- FIGURA 2: LINHA DO TEMPO DO SELO UNICEF}

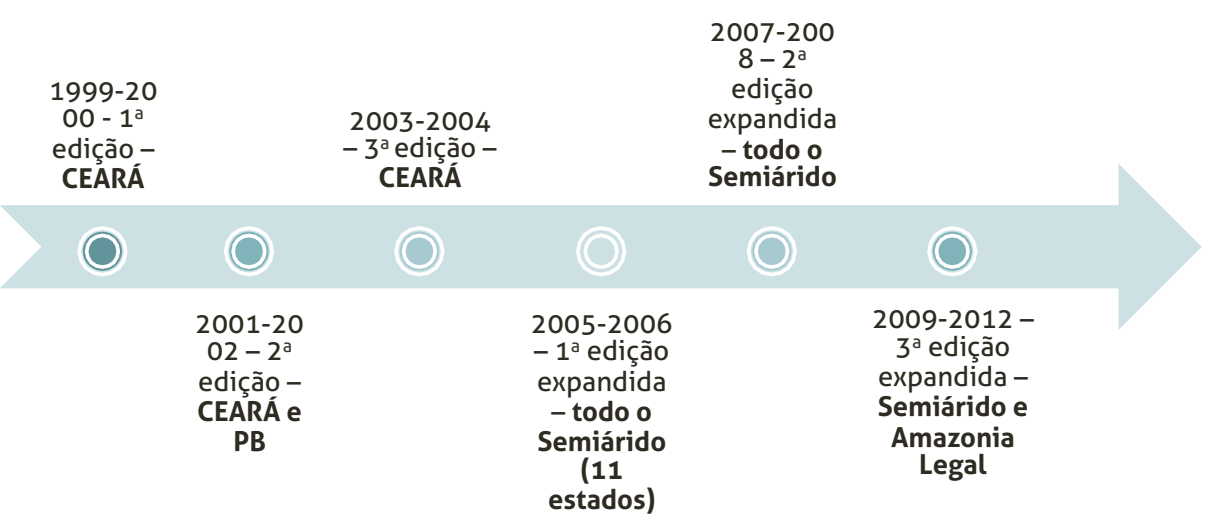

16 BRASIL. Presidência da República. Lei n 8.069, de 13 de julho de 1990. Disponível em: <http://www.planalto.gov. br/ccivil_03/leis/l8069.htm>. Acesso em: nov. 2014.

17 UNICEF. Disponíveis em: <http://www.selounicef.org.br/_selounicef.php?op=4>. Acesso em: 07 ago. 2014 
As edições do Selo foram alteradas ao longo do tempo, no sentido de aprimorar seu desenho e sua compreensão, a partir de exercícios de avaliações internas que colhiam feedback dos diversos parceiros. Além disso, identifica-se um esforço do UNICEF em produzir, disponibilizar na internet ${ }^{18}$ e/ou distribuir aos municípios uma série de materiais no sentido de aprofundar as orientações. São exemplos: os Cadernos Metodológicos, o Regulamento do Selo, o Termo de Adesão, spots de lançamento e mobilização, boletins informativos mensais, os cadernos Cidadania dos adolescentes, Políticas públicas, Guia Educação para a convivência com o Semiárido, Guia Cultura e identidade: Comunicação para a igualdade étnico-racial, Guia Esporte e cidadania, Guia Comunicação, direitos humanos e infância e o Manual de identidade visual.

\section{PARTES INTERESSADAS}

Os principais stakeholders envolvidos na implementação do Selo, e seus principais interesses, são:

- Crianças e adolescentes dos municípios: beneficiários finais e participantes da iniciativa.

\section{- Atores municipais:}

- Prefeito: como líder do poder público municipal, interessa-se pelo Selo pelas externalidades positivas que pode gerar em termos de recursos e parcerias adicionais e o reconhecimento de sucesso na realização de políticas públicas.
- Secretários: responsáveis pelas políticas municipais, têm interesse em dar a elas maior visibilidade e melhorar a qualidade de sua implementação por meio de uma maior integração.

- Conselhos municipais (em especial CMDCA): interessados em compreender seu papel e qualificar sua atuação.

- UNICEF: além de reforçar as estratégias do Programa de País, o Selo é um instrumento de advocacy que dá maior visibilidade à causa da defesa dos direitos das crianças e adolescentes.

- Governo federal: interesse em meLhorar a qualidade da implementação das políticas voltadas à C\&A nos municípios, por meio de uma melhor articulação intersetorial e de uma maior participação da sociedade, fortalecendo a democracia.

- Governos estaduais: interesse em reforçar seu papel junto aos municípios na implementação de políticas voltadas à C\&A.

- Financiadores: maior visibilidade e alcance de suas políticas de responsabilidade social, com melhor uso de seus recursos.

- Sociedade civil organizada (ONGs): pela possibilidade de participação nas discussões e definições catalisadas pelo 10 Fórum e de firmar parcerias em torno de suas causas.

\section{STATUS DE IMPLEMENTAÇÃO}

Encontra-se atualmente em implementação a edição 2013-2016 do Selo UNICEF 
que, assim como a edição finalizada de 2009-2012, abrange as regiões do Semiárido Brasileiro e da Amazônia Legal.

\section{A AVALIAÇÃO}

\section{PROPÓSITO DA AVALIAÇÃO}

O propósito da avaliação foi apoiar o Escritório do UNICEF no Brasil (Brazil Country Office - BCO) com o aporte de subsídios para introduzir melhorias no apoio a políticas públicas municipais focadas em equidade, que garantam os direitos de crianças e adolescentes, em especial os mais desfavorecidos e excluídos, por meio da promoção do Selo como metodologia chave. A avaliação pretendia, assim, testar a hipótese de que o Selo pode apoiar os municípios na execução das prioridades e políticas nacionais, no contexto do sistema federativo brasileiro.

O público-alvo da avaliação compõe-se, portanto, do BCO, a equipe gestora do UNICEF Brasil, os parceiros, os stakeholders e os tomadores de decisão-chave. Como audiência secundária, estão as equipes do Escritório Regional no Panamá e Escritório Brasil, entre outras organizações internacionais da América Latina e demais regi- ões. Os resultados deverão contribuir para o processo decisório interno ao UNICEF e promover maior accountability por desempenho e alcances do Selo no Programa de País. Poderão ainda ser utilizados para gerar produtos adicionais adequados a diferentes propósitos (por exemplo: instrumento de advocacy para futuros financiamentos, mobilização em torno do Pacto e da ACA, cooperações sul-sul, advocacy para incrementar a participação pelos municípios) e audiências (potenciais financiadores, municípios elegíveis, governos estaduais, governo federal e outros países interessados em replicar a experiência brasileira). ${ }^{18}$

\section{OBJETIVOS DA AVALIAÇÃO}

A avaliação visa identificar o valor agregado da metodologia do Selo e suas contribuições principais, bem como a documentar boas práticas e lições aprendidas de forma a apoiar estratégias futuras de continuação e ampliação. Busca analisar a implementação do Selo no nível municipal e seus efeitos de curto prazo, as lições aprendidas nos níveis federal, estadual e municipal, resultando inclusive na elaboração de recomendações para as próximas edições ou outras iniciativas semelhantes. 


\section{ESCOPO E CRITÉRIOS DA} AVALIAÇÃO

Uma vez que o foco da avaliação do Selo é o aprendizado e a inovação visando avaliar o alcance de resultados para a garantia dos direitos de criancas e adolescentes de forma participativa, a análise considerou: a conceitualização do Selo como ferramenta de mobilização e implementação de uma agenda de equidade para crianças e adolescentes; a implementação do Selo no nível municipal e seu impacto abrangente em termos de apoio à implementação de compromissos internacionais (Programa de País e Objetivos de Desenvolvimento do Milênio - ODM); prioridades de desenvolvimento nacionais e políticas publicas por meio do envolvimento das lideranças locais e processos de participação social; como o Selo foi introduzido, gerenciado e implementado nas diferentes edições; que impacto tem tido e continua a ter e como este impacto se relaciona com os pontos de políticas; lições aprendidas nos níveis federal, estadual e municipal, e como o aprendizado das experiências passadas se reflete no Selo atual e como pode ser usado para aprimorar a iniciativa nas edições atual e futuras.

Os critérios utilizados para a Avaliação do SELO UNICEF, relacionados a seguir, foram definidos em consonância com os manuais, conceitos e normas utilizadas pelo Grupo de Avaliação das Nações Unidas
(UNEG) e Unidade de Monitoramento e Avaliação do Escritório UNICEF Brasil.

- Relevância: em que medida os conceitos e objetivos do Selo foram consistentes com as demandas do país, estados e municípios, bem como com a agenda global relacionada aos ODMs e inequidades;

- Efetividade: em que medida os objetivos do Selo em edições passadas foram atingidos, tendo como base sua relevância;

- Eficiência: em que medida os recursos do Selo foram implementados para contribuir com os melhores resultados possíveis;

- Sustentabilidade: em que medida os benefícios do Selo permanecem após o processo ser finalizado, em curto, médio e longo prazo;

- Impacto: em que medida os efeitos primários e secundários na situação de crianças e adolescentes nos municípios participantes, incluindo 0 desenvolvimento de capacidades, mobilização social, gênero, governança etc., podem ser atribuídos ao processo do Selo.

Adicionalmente, a avaliação considerou critérios transversais, tais como: desenvolvimento de capacidades; apropriação; mobilização social; gênero; governança; gestão de programa e desenvolvimento de parcerias. 


\section{ABRANGÊNCIA DA AVALIAÇÃO}

Em termos temporais, o foco da avaliação foi sobre a edição 2009-2012, tendo como insumos, além de todo o arcabouço documental referente às edições anteriores e atual (documentos metodológicos e relatórios de resultados), os dados quantitativos de todos os municípios relativos a esta edição (2009-2012), o estudo "Estimativa de Resultados da Iniciativa Selo UNICEF em Nível Municipal", elaborado pelo consultor Lucio Fittipaldi Gonçalves em 2013, e os resultados das pesquisas qualitativas.

Para as pesquisas qualitativas, foram realizadas entrevistas com diversos representantes do UNICEF da sede e dos escritórios regionais (ou zonais) no SAB e na Amazônia Legal e com autoridades e gestores da administração pública federal e estaduais. Além disso, foram feitos 8 estudos de caso de municípios visitados, conforme critérios de seleção que buscavam classificar os municípios de acordo com tipologias que refletissem seu desempenho e seu nível de envolvimento com a metodologia do Selo. Nestes municípios envolveram-se 264 pessoas no processo de avaliação. Posteriormente, foram realizados 3 grupos focais, sendo um no estado do Ceará, com a participação de 7 municípios, um na cidade de Recife, com participação de 6 municípios de 6 estados, e um último em Belém, com a participação de outros 6 mu- nicípios de 6 estados. Com isso, todos os participantes da iniciativa do Selo, das regiões do Semiárido e da Amazônia Legal, foram contemplados com instrumentos qualitativos, totalizando uma participação de 327 pessoas, sendo 66\% mulheres.

Os estudos quantitativos, por sua vez, abrangeram o universo de municípios do Semiárido e da Amazônia Legal, participantes e não participantes do Selo na edição 2009-2012.

\section{METODOLOGIA}

Os termos de referência dos trabalhos definiam que a avaliação deveria ser realizada de acordo com a Política de Avaliação do UNICEF. Introduziam, ainda, algumas ideias e premissas relativas à metodologia: primeiramente, em termos de abordagem geral, estabeleciam que seria uma avaliação formativa, ou seja, de uma iniciativa em evolução que aprende com seu processo, com um componente somativo, ou seja, que realiza um balanço acumulado dos resultados. Com relação ao processo, sugeria-se que fosse um misto de avaliação participativa e de análise documental. Quanto às fontes de dados, o UNICEF definiu as fontes primárias como sendo as planilhas produzidas pelo processo interno de avaliação do Selo, entrevistas e discussões com a equipe do UNICEF e com os atores-chave; e, como fontes secundárias, a vasta documentação apresentada. 
Os métodos de coleta de dados e informações seriam: revisão documental, dados coletados em bases oficiais e nacionais para indicadores selecionados, dados coletados em visitas de campo em processos participativos e entrevistas semiestruturadas. Os métodos de coleta de dados e informações deveriam ser coerentes com os critérios e questões de avaliação definidos.

As análises de dados deveriam considerar as informações quantitativas e qualitativas obtidas em visitas e entrevistas de campo.

As técnicas de avaliação de impacto deveriam ser detalhadas no relatório inicial, incluindo: métodos quantitativos e quali- tativos ou integrados; contrafactuais (grupo de melhores versus piores e/ou grupo de tratamento versus grupo de controle); linha de base e outras informações consideradas relevantes.

Todo o processo de avaliação seria validado pelos especialistas em monitoramento e avaliação do UNICEF Brasil e pelo Comitê de Acompanhamento da Avaliação, de forma a assegurar que os dados e informações utilizadas e as conclusões fossem consistentes e baseados em evidências.

\section{O PROCESSO AVALIATIVO}

O relatório inicial apresentou a proposta do processo avaliativo, composto pelas seguintes fases:

\section{- FIGURA 3: PROCESSO AVALIATIVO}

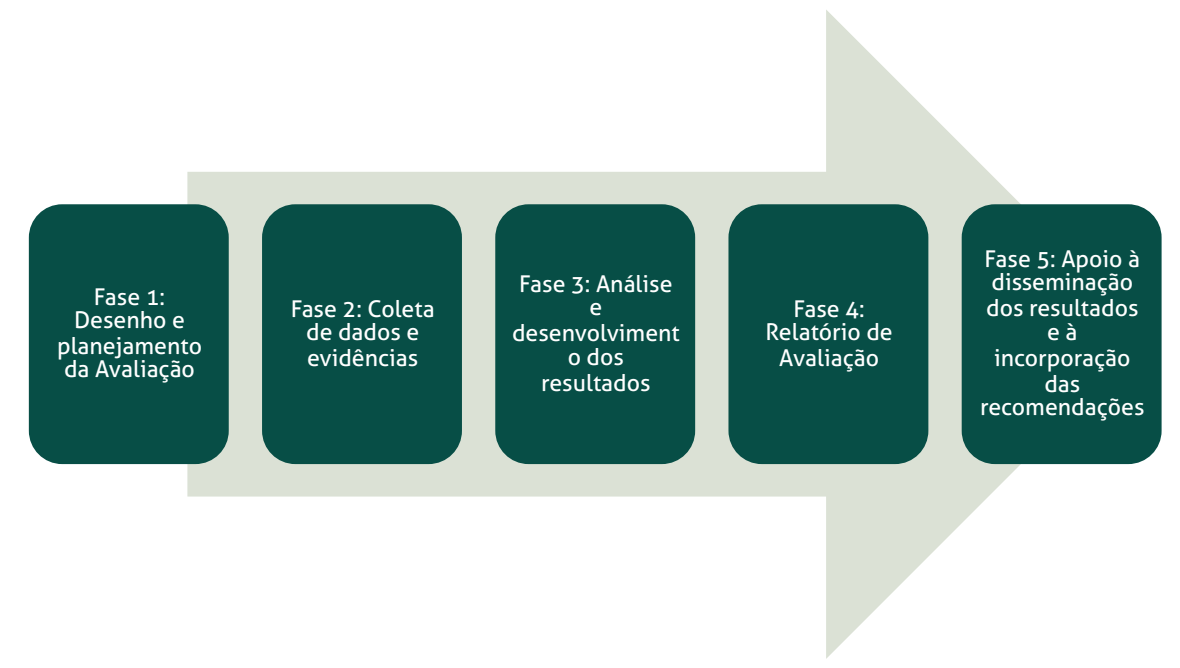


A primeira etapa da avaliação (desenho e planejamento) suscitou discussões definidoras da estratégia metodológica. Incluiu a estruturação da equipe de avaliadores, o levantamento inicial de documentos e informações, as primeiras reuniões com a equipe de M\&A do UNICEF, a reconstrução e validação da Teoria de Mudança, a matriz de avaliação, os protocolos das visitas de campo e o Plano de Trabalho.

A equipe de avaliação foi composta por 8 profissionais sênior, sendo: 1 coordenadora; 1 especialista em monitoramento e avaliação de projetos (com experiência em avaliações para o sistema ONU); 1 administradora pública com especialização em geografia humana e organização do espaço; 1 estatística; 1 historiadora com mestrado em Ciências Sociais e doutorado em Sociologia; 1 socióloga; 1 analista de informações; e 1 técnico em informação.

\section{OS MÉTODOS DE COLETA PROPOSTOS}

Foram propostos métodos com enfoque quantitativo e qualitativo, de acordo com sua pertinência para cada critério de avaliação. A estratégia de comunicação adotada pelo UNICEF ao longo dos anos traz a necessidade de traduzir em números palpáveis os resultados da avaliação. Por outro lado, para compreender aspectos como o que funciona ou não funciona, os fatores que levaram diversos municípios ao sucesso e os desafios da implementação da metodologia, ou seja, explicar o que os números revelavam, era necessário adotar métodos qualitativos.

Em resumo, para cada critério de avaliação, foi possível utilizar métodos de coleta de dados e informações qualitativos e quantitativos e combinar os resultados nas análises realizadas, conforme quadro a seguir:

\section{- QuUADRO 2: CRITÉRIOS DE AVALIAÇÃO E MÉTODOS}

\begin{tabular}{|c|c|c|}
\hline $\begin{array}{l}\text { CRITÉRIOS DE } \\
\text { AVALIAÇÃO }\end{array}$ & MÉTODOS QUANTITATIVOS & MÉTODOS QUALITATIVOS \\
\hline Relevância & $\begin{array}{l}\text { Análise do alcance de resultados dos mu- } \\
\text { nicípios versus grau de envolvimento na } \\
\text { metodologia do Selo (2009-2012) - por } \\
\text { região, estado e grupo. }\end{array}$ & $\begin{array}{l}\text { Análise documental e entrevistas com os di- } \\
\text { versos grupos de stakeholders (ver item 1.8); } \\
\text { reuniões nos municípios visitados com a par- } \\
\text { ticipação de diversos grupos envolvidos no } \\
\text { processo; grupos focais com representantes de } \\
\text { municípios e estados }\end{array}$ \\
\hline Eficácia & $\begin{array}{l}\text { Análise de correlação entre resultados } \\
\text { alcançados e grau de capacidades institu- } \\
\text { cionais dos municípios - por região, estado } \\
\text { e grupo; } \\
\text { Análise do alcance de resultados dos mu- } \\
\text { nicípios versus grau de envolvimento na } \\
\text { metodologia do Selo (2009-2012) - por } \\
\text { região, estado e grupo. }\end{array}$ & $\begin{array}{l}\text { Análise documental (relatórios de progresso do } \\
\text { Selo) } \\
\text { Entrevistas com os diversos grupos de stakehol- } \\
\text { ders (ver item 1.8); reuniões nos municípios vi- } \\
\text { sitados com a participação de diversos grupos } \\
\text { envolvidos no processo; grupos focais com re- } \\
\text { presentantes de municípios e estados }\end{array}$ \\
\hline
\end{tabular}

Revista Brasileira de Monitoramento e Avaliação | Número 8 | Julho-Dezembro de 2014 


\section{CRITÉRIOS DE \\ AVALIAÇÃO

Análise do cumprimento das etapas me-

Eficiência todológicas pelos municípios por região, estado e grupo

Impacto

\section{Un}

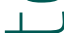

$+$

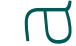

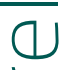

Sustentabilidade e apropriação

No caso do $S A B$, análise dos participantes e ganhadores a partir da edição de 2005 e, ganhadores da última edição (2009-2012)

e inscritos na edição vigente (2013-2016).

Suficiência de Recursos e tempo: entrevistas aos atores municipais, estaduais e federais e reuniões de grupo (visitas de campo e grupos focais) e staff UNICEF

Identificação, por meio de entrevistas, de como estariam as políticas locais sem o advento do Selo, das mudanças que já podem ser percebidas pelos diversos stakeholders entrevistados e as evidências de mudanças de longo prazo alcançadas ou com alta probabilidade de ocorrer após 5 a 10 anos da finalização da Edição 2009/2012. Identificação dos efeitos negativos e não desejados.

Entrevistas com os atores municipais, estaduais e federais e reuniões de grupo (visitas de campo e grupos focais) e staff UNICEF
Gênero e minorias

Gestão da Iniciativa
Análise documental dos instrumentos metodológicos e entrevistas com os atores municipais (visitas de campo e grupos focais)

Análise documental dos instrumentos metodológicos e relatórios de resultados (voltados aos financiadores)

Entrevistas com todos os stakeholders
Os métodos de coleta descritos no quadro estão mais bem detalhados a seguir:

(i) Análise documental Enquadramento e análise de documentos, relatórios, relatórios de doadores, pesquisas e dados relacionados ao Selo UNICEF.

(ii) Coleta de dados de fontes secundárias oficiais $^{19}$ e dos bancos de dados do UNI$\mathrm{CEF}^{20}$ comparando os municípios participantes e aqueles que não participaram, tentando identificar possíveis tendências entre esses dois grupos de municípios. (iii) Entrevistas em profundidade com stakeholders envolvidos no Selo, incluindo:

- Municípios: prefeitos e ex-prefeitos; articuladores e ex-articuladores municipais do Selo, secretários de saúde, educação e assistência social; membros dos Conselhos Municipais de Direitos das Crianças e Adolescentes (CMDCAs) e Conselhos Tutelares; lideranças jovens, lideranças femininas, representantes de ONGs locais, entre outros. 
- Estados: representantes de conselhos estaduais de direitos das Crianças e Adolescentes (CEDECAs); articuladores estaduais do Pacto do Semiárido e da ACA; articuladores estaduais do Selo, secretarias de estado, parceiros implementadores, equipe do UNICEF que participou do Selo, facilitadores de fóruns comunitários, moderadores, entre outros.

- Esfera Nacional: equipe do UNICEF no Brasil (atual e envolvida nas edições passadas, mesmo não pertencendo mais ao staff), parceiros na esfera federal relacionados ao Selo, incluindo patrocinadores, ONGs envolvidas nacionalmente.

- Esfera Internacional: staff do UNICEF no escritório regional (TACRO).

(iii) Grupos focais nos municípios visitados para efeito de estudos de caso, reunindo representantes dos diversos stakeholders locais que tenham participado da implementação do Selo, edição 2009-2012.

(iv) Grupos focais nos estados, reunindo ex-prefeitos e ex-articuladores de municípios que tenham sido bem sucedidos no Selo em mais de uma edição, quando possível.
As visitas de campo, que foram a base dos estudos de caso, incluíram entrevistas em profundidade a atores municipais, grupos focais locais e entrevistas em profundidade com atores estaduais. Tais atividades tiveram por objetivo vivenciar e compreender o contexto e a realidade local e os fatores de sucesso e insucesso na implementação da iniciativa do Selo. Os municípios foram selecionados de comum acordo com o Comitê de Acompanhamento da Avaliação, sendo que a ideia inicial seria visitar 8 municípios, sendo 4 do Semiárido e 4 da Amazônia Legal. Em um segundo momento, a proposta evoluiu para visitar 14 municípios, conforme critérios a seguir.

Obviamente, o número de municípios proposto para visitas não consistia em uma amostra estatisticamente representativa do universo de municípios participantes na iniciativa. A proposta não se baseava em estudo experimental, e, sim, na utilização de um desenho de estudo de caso que tinha por objetivo entender mais a fundo os processos, eventos e situações ocorridas durante a implementação do Selo e como a metodologia e seus resultados foram absorvidos pelos municípios.

20 Com os resultados dos indicadores por município e com registros sobre o desenvolvimento do processo de implementação do Selo.

Revista Brasileira de Monitoramento e Avaliação | Número 8 | Julho-Dezembro de 2014 


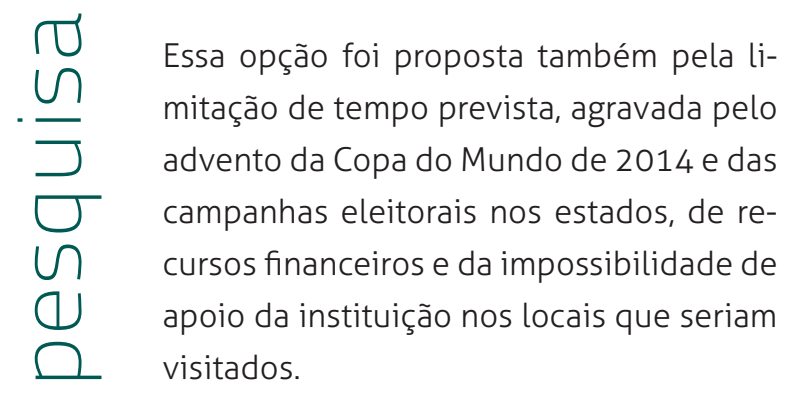

(1)

○

U

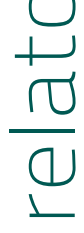

\section{Para o Semiárido brasileiro}

- Municípios que tiveram esforço (participação e envolvimento) baixo e performance alta, buscando investigar o que fizeram além da iniciativa do Selo para alcançar o bom resultado - 2 municípios, sendo 1 do grupo $01^{21}$ e outro do grupo 05;

- Municípios que tiveram esforço (participação e envolvimento) alto e performance baixa, buscando investigar o que faltou fazer no âmbito do Selo ou fora dele para alcançar melhores resultados -2 municípios, sendo 1 do grupo 01 e outro do grupo 05.

- Municípios que tiveram esforço (participação e envolvimento) alto e performance alta, buscando investigar os fatores de sucesso - neste grupo seriam estudados ganhadores e não ganhadores do Selo. Para o sub-grupo dos não ganhadores, a intenção era investigar o que fez com que os municípios chegassem ao final da metodologia e não ganhassem o Selo? Para o sub-grupo dos ganhadores, foi identificado um conjunto de $7 \mathrm{mu}$ nicípios, do Ceará, que ganharam o Selo desde o ano 2000 (totalizando 6 êxitos), merecendo uma atenção especial. Quais foram as condições que provocaram tamanho sucesso? - 4 municípios, sendo 2 do grupo 01 e 2 do grupo 05, sendo 2 não ganhadores e 2 ganhadores (um dos municípios deste último sub-grupo seria um dos municípios contemplados com 6 Selos, ou seja, ganhadores em todas as edições desde 2000).

Optou-se por não visitar o grupo de esforço baixo e performance baixa, pelo entendimento de que não teriam muito a contribuir com a investigação da causalidade entre os avanços e o processo de implementação do Selo.

Premissa: O grupo 01 seria considerado um grupo homogêneo de municípios mais "desenvolvidos" e o grupo 05, o oposto.

Total de municípios a serem visitados no Semiárido: 8.

\section{Amazônia Legal}

Pelo fato dos municípios da Amazônia Legal terem participado apenas da última edição (2009-2012), os critérios para classificação de envolvimento e desempenho foram diferentes dos aplicados para municípios do Semiárido, conforme detalhado a seguir.

\section{- Envolvimento baixo (realizou ape- nas o 10 Fórum) / não ganhadores: 2 municípios, sendo um do grupo 01 e um do grupo 05.}


- Envolvimento alto (chegou a realizar os 2 Fóruns) / não ganhadores: 2 municípios, sendo um do grupo $01 \mathrm{e}$ um do grupo 05.

\section{- Envolvimento alto e ganhadores do} Selo: 2 municípios, sendo um do grupo 01 e um do grupo 05.

Total de municípios a serem visitados na Amazônia Legal: 6.

A escolha dos municípios deveria levar em consideração as longas distâncias entre eles (especialmente na região amazônica), o tempo disponível para a coleta de dados, as similaridades entre eles, o tamanho da equipe de coleta, o custo associado e a quantidade de informação a ser levantada com vistas ao objetivo da avaliação. Tal escolha seria determinante no processo de avaliação, favorecendo uma coleta independente e imparcial de dados, uma vez que seria realizada pela própria equipe de avaliadores, independentemente do UNICEF. Nesse contato, o objetivo seria garantir a participação do prefeito e de outros atores que participa- ram do Selo durante o tempo da equipe no município.

A opção por visitar os quatro tipos de municípios utilizando um desenho de estudo de caso, permitiu à equipe entender o que motivou os municípios a ganharem ou não o Selo, o que levou os municípios a desistirem e não participar do processo. A utilização deste desenho garantiu ainda a participação do maior número de stakeholders possível, como condição fundamental para uma escuta abrangente.

Os métodos de coleta de dados e informações utilizados permitiriam uma análise bastante completa considerando os critérios selecionados, os pontos de vista dos diversos atores envolvidos e uma triangulação dos achados, aumentando, assim, a confiabilidade do processo e da análise como um todo. Todos estes métodos se articulavam de uma forma clara na matriz de avaliação apresentada no Relatório Inicial, detalhando o número e quais seriam as pessoas entrevistadas, quais os dados quantitativos a serem coletados e outros detalhes técnicos.

21 O agrupamento dos municípios é feito a partir da análise de um conjunto de indicadores econômicos e sociais, que refletem as condições de vida das crianças e adolescentes, tais como: população, Produto Interno Bruto (PIB) e índices de pobreza. De acordo com o Índice de Agrupamento do Selo, foram definidos cinco grupos, sendo que o grupo 01 é dos municípios maiores e com melhores PIB e o grupo 05, o oposto.

Revista Brasileira de Monitoramento e Avaliação | Número 8 | Julho-Dezembro de 2014 
Após a entrega da primeira versão do Relatório Inicial, que consolidava a etapa de planejamento da avaliação, foram realizadas algumas reuniões para discutir a proposta apresentada com participação da equipe do UNICEF, do escritório Brasil (Brasília) e dos escritórios zonais, sendo que uma delas contou com a participação do Representante do UNICEF no Brasil. As equipes tiveram oportunidade de fazer sugestões, sendo que a principal delas referiu-se ao número de municípios a serem visitados. Primeiramente, foi questionada a escolha dos grupos 01 e 05, sugerindo incluir municípios também do grupo 03, e foi colocada pelos Coordenadores dos escritórios zonais a importância de incluir todos os estados no processo de avaliação, sendo importante visitar pelo menos um município de cada estado. Também foi sugerido um maior detalhamento dos métodos quantitativos de coleta e análise, aprofundados e apresentados oportunamente ao UNICEF.

Após alguns entendimentos entre a equipe e o UNICEF, ficou claro que não haveria suficientes recursos financeiros e tempo para visitas a 14 municípios, optando-se pela realização de visitas a 8 municípios e composição de 3 grupos focais especiais: o primeiro, realizado em Fortaleza/ CE, com os municípios do Ceará ganhadores do Selo em diversas edições desde 1999 (representando um grupo seleto de bem sucedidos). Um segundo, realizado em Recife/PE, com 6 municípios de 6 estados do Semiárido e o terceiro, realizado em Belém/PA, com 6 municípios de 6 estados da Amazônia Legal. Para os dois últimos grupos, foram selecionados municípios ganhadores e inscritos na edição 2013-2016. Este critério justificou-se pela necessidade de discutir mais profundamente as oportunidades de melhoria do processo de implementação do Selo, bem como os fatores de sucesso que levaram ao êxito esse conjunto de municípios.

O conjunto de municípios participantes dos grupos focais e os municípios visitados deu à avaliação a abrangência desejada, oportunizando, dentro das limitações existentes, a participação de todos os estados envolvidos. Em cada município foram realizadas seis entrevistas individuais (Prefeito, Secretário ponto focal do Selo, presidente do Conselho Municipal em Defesa dos Direitos das Crianças e Adolescentes - CMDCA, articulador(a) da edição 2009-2012, liderança jovem e liderança feminina) e uma reunião com participantes da edição 2009-2012 com a participação média de 30 pessoas.

As entrevistas com os diversos stakeholders, as reuniões e grupos focais com municípios permitiram a participação total de 327 pessoas, representantes de todos os stakeholders listados na descrição do objeto, caracterizando esse processo como de alta participação.

\section{ANÁLISE}

Os métodos de análise dos resultados, a partir da coleta de evidências e da matriz de avaliação, estão resumidos a seguir: 


\section{- Eficácia}

Para avaliação da eficácia, as principais questões avaliativas definidas foram: "Em que medida o Selo foi capaz de apoiar a obtenção de resultados das políticas nacionais destinadas aos direitos da C\&A em nível local?" e "A estratégia e as atividades realizadas no Selo contribuem, no nível local, para a melhoria da qualidade da gestão de políticas públicas ou programas nacionais voltados à defesa da C\&A?)". As bases de julgamento foram os dados sobre o alcance de resultados pelos municípios, seu grau de envolvimento com a metodologia do Selo (até que fase da metodologia o município conseguiu avançar), disponibilizados pelo UNICEF, e o nível de capacidade institucional dos municípios, analisado a partir de oitenta variáveis. Obviamente, os resultados são diversos para o conjunto de municípios participantes. No entanto, foi possível realizar análises por região atendida (Semiárido e Amazônia Legal), por estado e por grupo de municípios.

Assim, a partir dos dados sobre desempenho e estudos avaliativos prévios ${ }^{22}$ e, ainda, de outros dados disponíveis em fontes oficiais, foram realizadas análises quantitativas, complementadas por evidências qualitativas coletadas nas diversas entrevistas e grupos focais realizados. Para que essas análises pudessem contribuir às respostas das questões avaliativas, era necessá- rio não apenas analisar o desempenho do conjunto de municípios, de forma conjunta e desagregada, como também estudar sua correlação com fatores significativos e determinantes que pudessem explicar tais desempenhos. Tais fatores estariam relacionados aos seus insumos e atividades.

\section{- Eficiência}

A análise de eficiência teve como pano de fundo a seguinte questão: "Os recursos (funding, normas, recursos administrativos e técnicos e tempo) foram usados da forma de melhor custo-eficiência para alcançar de modo satisfatório as políticas de direito de C\&A?". Pela dificuldade em se aferir o montante de investimento ou custo de cada edição do Selo UNICEF por parte das diversas fontes que o financiam, optou-se por definir como medida de eficiência o alcance do processo de implantação do Selo nos diversos municípios do SAB e da Amazônia Legal. Todos eles são convidados a participar do Selo, no entanto, nem todos se inscrevem. Esta seria uma medida de eficiência da atividade de mobilização dos municípios. A partir da inscrição, há municípios que não chegam a realizar o 10 Fórum. Outro conjunto chega a atender todas as condições, mas não ganha o Selo. Por fim, 23\% dos municípios que se inscrevem, em média, ganham o Selo. 


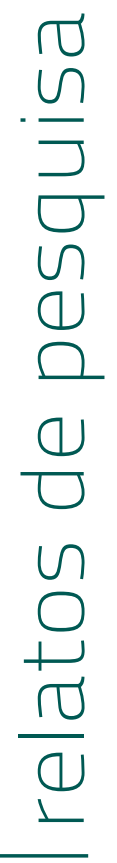

Considerando que um dos grandes resultados do Selo é o desenvolvimento de capacidades locais e a introdução na necessidade de se trabalhar de forma articulada em nível local e, ainda, que é por meio do processo metodológico que esses ganhos são alcançados, um dos indicadores de eficiência analisados como nível de aproveitamento é o percentual de municípios que atenderam todas as condições em relação aos inscritos (e ganharam o Selo ou não). Isso se justifica ainda pela já observada correlação entre desempenho e grau de envolvimento no processo do Selo.

\section{- Apropriação}

Uma das mais importantes questões da avaliação é: "O Selo foi apropriado pelas municipalidades e os resultados vêm se mantendo ao longo dos últimos anos?". Para responder a esta pergunta pode-se valer da base de dados apresentada pelo UNICEF, que disponibiliza a informação, para as duas regiões, dos municípios que participaram e ganharam o Selo. No caso do SAB, é possível analisar participantes e ganhadores a partir da edição de 2005-2006 e, no caso da Amazônia Legal, participantes e ganhadores da última edição (2009-2012) e que se inscreveram na edição vigente (2013-2016).

As análises quantitativas realizadas para os três critérios acima (eficácia, eficiência e apropriação) foram associadas às respostas a questões obtidas com as entrevistas que permitiram interpretar, identificar melhoras a serem realizadas e dar insumos para interpretar algumas hipóteses e números alcançados.
Quanto ao critério impacto, optou-se pela não utilização de um método quantitativo, diferentemente das definições iniciais do Termo de Referência. Uma das questões da matriz de avaliação é: "O quanto o impacto alcançado nos municípios poderia ser atribuído à metodologia?", em outras palavras, seria possível descobrir o quanto poderia ser atribuída ao Selo a melhoria da qualidade de vida das crianças e adolescentes? O que teria acontecido nos municípios sem a metodologia do Selo?

Para responder a essa pergunta, poderia ter sido realizado um estudo quantitativo de avaliação de impacto, do tipo experimental ou quasi-experimental, que buscasse aferir, para municípios comparáveis, a diferença entre o impacto que municípios participantes do Selo tiveram (grupo de tratamento) e o impacto em municípios não participantes (grupo de controle). Ou seja, investigar a relação de causa e efeito entre o Selo e a melhoria da qualidade de vida de seu público-alvo, por meio da seleção de alguns indicadores de impacto e análise de sua evolução em municípios semelhantes comparando participantes e não participantes do Selo. No entanto, para aplicar esse tipo de metodologia com o rigor técnico necessário, seria preciso isolar a iniciativa do Selo dos outros inúmeros fatores que teriam influência na melhoria da qualidade de vida das crianças e adolescentes, o que seria tarefa extremamente complexa, pois os municípios apresentam diversas diferenças, não apenas em características demográficas e socioeconômicas, como também as diferenças que estão sendo analisadas de forma mais profunda. 
O conjunto de municípios abrangidos pelo Selo apresentm diferenças de contexto político, culturais e de arranjos institucionais onde estão envolvidas, no caso do Selo, quase oitenta variáveis. Apresentam também diferenças relativas às intervenções que podem estar ocorrendo naquele território com objetivos comuns ao do Selo: programas e projetos públicos federais, estaduais e municipais; ações do setor privado; ações da sociedade civil organizada; ações de outras agências multilaterais. Deste modo, considerou-se que uma análise do tipo quasi-experimental não traria ao trabalho de avaliação o rigor metodológico suficiente para concluir pela atribuição ao Selo da melhoria da qualidade de vida das C\&A.

O documento "Impact Evaluation in UN Agency Evaluation Systems: Guidance on Selection, Planning and Management" (Avaliação de Impacto nos sistemas de avaliação das agências ONU: guia para Seleção, Planejamento e Gestão), ${ }_{1}^{33}$ publicado pelo Grupo de Avaliação das Nações Unidas UNEG) em agosto de 2013, corrobora com esta visão, embasando-a de forma teórica bastante consistente.uNo capítulo 3, o Guia traz uma discussão sobre métodos utilizados em avaliações de impacto, explicando que desenhos experimentais e quasi-experimentais são apropriados para investigar se uma intervenção fez a diferença e em que extensão um específico impacto pode ser atribuído a ela. No entanto, Leeuw e Vaessen ${ }^{24}$ afirmam que métodos que consideram este tipo de desenho são particularmente apropriados para avaliações de "iniciativa de componente singular com objetivos explícitos" (single-strand initiatives). Tomemos como exemplo a transformação de um campo de milho após a introdução de uma nova tecnologia. Neste exemplo, pode-se imaginar dois campos de milho, semeados com o mesmo lote de sementes, sob as mesmas condições de irrigação, insolação e fertilização. Em um desses campos se introduz uma nova tecnologia agrícola e no outro, não. Ao comparar os resultados e observar uma mudança na produtividade ou tamanho das espigas, é possível afirmar, com reduzida margem de erro, que os resultados da mudança são atribuídos à introdução da nova tecnologia. Isso ocorre porque esta intervenção pôde ser isolada, manipulada, e medida. Assim, desenhos experimentais ou quasi-experimentais podem ser apropriados para medir relações

23 Preparado pela Força de Trabalho de Avaliação de Impacto da UNEG com assessoria voluntária de Dr. David Todd, Dra. Patricia Rogers, Burt Perrin, Dr. Michael Spilsbury e Dugan Fraser.

24 NONIE. Impact Evaluation and Development. In: LEEUW, F.; VAESSEN, J. Nonie Guidance on Impact Evaluation, 2009. 
causais entre essas iniciativas single-strand e seu efeitos. Além disso, segundo White e Phillips, ${ }^{26}$ esses métodos são mais adequados para avaliações com grande universo e grande amostra, ou seja, a população geral afetada e a amostra selecionada devem ser grandes.

Esses tipos de intervenção (single-strand initiatives), adequadas para o uso desses métodos, não são o ambiente usual de muitas organizações do sistema ONU. Além disso, estudos de larga escala que usam complexas análises estatísticas costumam ser de uma dimensão financeira raramente disponível. Um estudo da Força Tarefa de Avaliação de Impacto do UNEG mostrou que em 2010 apenas trê3 áreas da UNEG comissionaram avaliações de impacto utilizando métodos experimentais ou quasi-experimentais. Segundo o Guia:

"[...] como alternativa às abordagens estatísticas mais complexas, análises quantitativas básicas e bases de dados existentes e/ou análises de pesquisa podem dar importante contribuição ao desenvolvimento da história da diferença que a intervenção provocou. Tais análises podem ser realizadas com o uso de uma estatística descritiva como tabulações transversais ou inferências estatísticas com a análise da variança para comparar os significados de diferentes grupos. Diversos tipos de intervenções não são apropriados para abordagens quantitativas complexas, como métodos experimentais ou quasi-experimentais, como programas com uma gama extensiva de escopo e que incluam temas, setores ou áreas geográficas transversais. Múltiplas agências, múltiplas causas simultâneas para os resultados e mecanismos causais diferindo através de contextos e complexidades. Muitos trabalhos das agências ONU são realizados em ambientes de alta complexidade. Muitas vezes pode ser possível quebrar tais intervenções em componentes mais simples, de forma a permitir uma análise quantitativa. No entanto, para uma grande parte 
dessas intervenções, métodos quantitativos responderão apenas a parte das questões relacionadas a impacto. Isso dará espaço a desenhos de avaliação centrados em métodos qualitativos. Há uma gama de métodos qualitativos que têm sido considerados úteis em avaliações de impacto incluído: avaliação realística, metodologia de eliminação geral, trilha do processo e análise de contribuição."

O Relatório Preliminar de Avaliação (em análise pelo UNICEF) incluiu: os resultado) da avaliação; as conclusões de cada critério avaliado, as lições aprendidas e uma lista de recomendações dirigidas às diversas categorias de stakeholders.

\section{CONCLUSÃO}

A iniciativa do Selo UNICEF ocorre em um ambiente institucional de alta complexidade pelo contexto político, institucional, cultural e sóci-econômico dos diversos entes federados, diversidade de atores envolvidos, papeis que exercem na inicia- tiva, abrangência e dimensão do processo metodológico. Esta diversidade levou à necessidade de realizar um processo de avaliação participativo, apesar de não ter havido oportunidade de discutir previamente com os stakeholders o método a ser empregado, exceto com o staff do UNICEF.

A necessidade de empregar métodos qualitativos e quantitativos para coleta de dados e informações e analisar os diferentes critérios de avaliação foi consequência tanto das diretrizes impostas pelos guidelines do UNEG e do próprio UNICEF, quanto para dar legitimidade aossresultados, que deveriam ser totalmente baseadas em evidências.

O fato de contar com uma equipe multidisciplinar, que trabalhou de forma integrada em todas as etapas da avaliação e na interface com o UNICEF, imprimiu aos trabalhos um caráter de múltiplos olhares, aumentando a capacidade de formulação e de análise.

25 WHITE, H.; PHILLIPS, D. Addresssing attribution of cause and effect in small $\mathbf{n}$ impact evauations: towards an integrated framework. 3.ed. Nova Déli, 2012. 